\section{Pacific Northwest Agricultural Safety and Health Center}

\section{February 2018}

\section{What are our priorities?}

The Pacific Northwest Agricultural Safety and Health Center (PNASH) is one of 11 agricultural research and prevention centers funded by the National Institute for Occupational Safety and Health (NIOSH). Founded in 1996, PNASH addresses local needs for our farming, fishing, and forestry work forces, and is now entering a new cycle (2016-2021) with multiple innovative research projects. PNASH works with partners in industry, labor, health services, professional organizations, and academia.

We focus on the needs of vulnerable populations including women, farmworkers, and immigrant forestry workers. Our current priorities include:

- Reducing exposure to high-risk pesticides in agricultural work and communities

- Preventing heat-related illness among agricultural workers

- Addressing serious injuries among dairy, forestry, and commercial fishing workers

\section{What do we do?}

- Provide training workshops and tools for safety
- Conduct field studies to evaluate new technologies, controls, and practices to reduce hazards.

- Work with industry partners and employees to identify and design system and workplace-based solutions. educators, health care providers, and industry professionals.

\section{What have we accomplished?}

- Demonstrated through research that new tower sprayers can reduce pesticide drift up to $35 \%$. In conducting this study, also developed novel methods for tracking pesticide drift using micronutrients.

- Released new forestry services educational resources in English and Spanish for employers and workers, including brief "Safety Talks."

- Measured improvement in vineyard worker health (including BMI, fat, and blood pressure) with team participation in our new Total Worker Health ${ }^{\circledR}$ intervention, "BeSuper! Agriculture." In English and Spanish.

- Develop analytical systems for surveillance research that bridge multiple agency data to assess trends and address hazards.

- Practice community-based and participatory action research to understand priorities, and partner in the development of injury and illness prevention programs.

- Mentor students in Bachelor's, Master's and PhD degree projects.

- Demonstrated the effectiveness of an Integrated Pest Management strategy for dairies to reduce dependence on pyrethroid pesticides for fly control. Resulted in adoption of the feedthrough larvicide.

- Conducted an ergonomic evaluation with workers using new mobile platform technology in tree fruit. Results showed a reduction in ergonomic stressors and physical work demands compared to the use of orchard ladders.

- Launched Ag Medicine, a new elearning course and lecture series developed for mid-level providers. Free with CME/CNE credits available.

\section{What's next?}

- Work with WA employers and workers on a work-based training curriculum and setting a national model to prevent sexual harassment for farmworker women. View video trailer.

- Provide a visual, interactive web-based database, enhancing access to NW agricultural injury, demographic, and geographic data.

- Develop a drift determinant model to assist orchardists in assessing risks in certain weather forecasts. We will be validating our data-driven research on the probability of pesticide drift with field studies.

\section{At-A-Glance}

The Pacific Northwest Agricultural Safety and Health Center conducts

research and promotes best health and safety practices for Northwest producers and workers in farming, fishing, and forestry. This snapshot shows recent accomplishments and upcoming work.

PNASH, located at the University of Washington School of Public Health in Seattle, WA, serves the Pacific Northwest

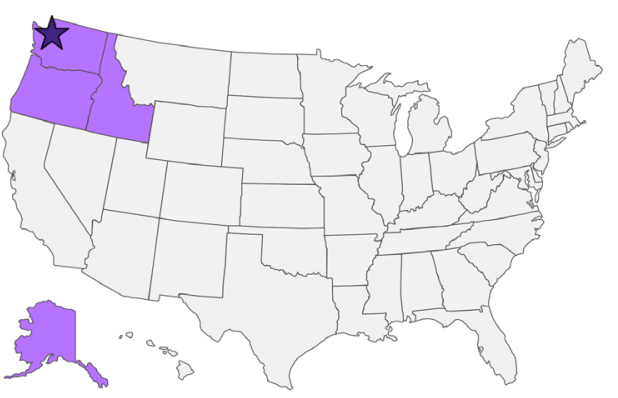

\section{Washington State 2009-2013 Injury Type}

$$
\text { All Industries } \quad \text { Agricultural }
$$

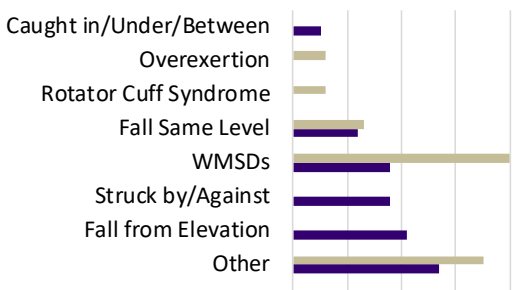

$\begin{array}{llllllllll}0 & 10 \% & 20 \% & 30 \% & 40 \% & 50 \%\end{array}$

Source: Washington State Dept. of Labor and Industries

Number of WA workers handling pesticides with hazardous exposure levels (based on cholinesterase depression)

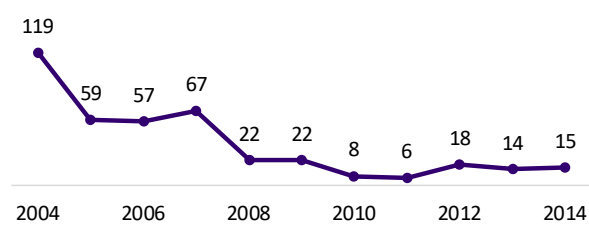

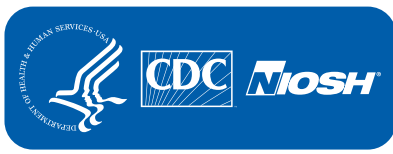

Centers for Disease Control and Prevention National Institute for Occupational Safety and Health
- Deliver and evaluate a training program on Slips, Trip and Fall prevention to WA Dairies in English and Spanish.

- Collaborate with WA dairies and 100 newly employed workers to assess if there is a "healthy dairy" effect, where workers adapt and develop immune benefits. (See quote to right).

- Introduce timely heat safety guidance to employers through an alert system hosted by partner, WSU Ag Weather Net.

ource: Washington State Dept. of Labor and Industries

"As the owner of a dairy farm, I am interested in the health of workers and feel that your research could shed light on novel methods of maintaining worker health in this work environment where microbial exposure is unavoidable."

- WA Dairy Owner 